Table 1. Interval between baseline BMD testing and the development of osteoporosis

\begin{tabular}{|c|c|c|c|c|}
\hline \multirow[t]{2}{*}{ Baseline BMD } & \multicolumn{2}{|c|}{$\begin{array}{c}\text { Mean interval to develop } \\
\text { osteoporosis } \\
\text { (year) }\end{array}$} & \multicolumn{2}{|c|}{$\begin{array}{l}\text { Mean interval to develop } \\
\text { osteoporosis in } 10 \% \text { of } \\
\text { each group (year) }\end{array}$} \\
\hline & Lumbar spine & Femur neck & Lumbar spine & Femur neck \\
\hline Normal & $9.4(9.29-9.49)^{\mathrm{a}}$ & $9.4(9.25-9.53)^{a}$ & $>10$ & $>10$ \\
\hline Mild osteopenia & $9.2(8.58-9.71)^{\mathrm{a}}$ & $9.1(8.94-9.22)^{\mathrm{a}}$ & 4.3 & $>10$ \\
\hline Moderate osteopenia & $7.9(6.94-8.76)^{\mathrm{a}}$ & $9.4(8.93-9.87)^{\mathrm{a}}$ & 2.5 & 7.5 \\
\hline Advanced osteopenia & $5.4(4.61-6.21)^{\mathrm{a}}$ & $8.6(7.68-9.50)^{\mathrm{a}}$ & 1.5 & 2.2 \\
\hline
\end{tabular}

BMD, bone mineral density. ${ }^{~}$ Mean $(95 \%$ confidence interval).

patients, 4 years in mild, 2 years in moderate, and 1 year in advanced osteopenic RA patients on the basis of L-spine BMD.

Disclosure of Interest: None declared

DOI: 10.1136/annrheumdis-2017-eular.4638

\section{SAT0138 OPTIMIZING TARGETED THERAPY: CAN PROMS FILL THE GAP BETWEEN PATIENTS- AND PHYSICIAN- PERCEIVED REMISSION IN RHEUMATOID ARTHRITIS}

Y. El Miedany ${ }^{1}$, M. El Gaafary ${ }^{2}$, N. El Arousi ${ }^{3}$, S.S. Youssef ${ }^{3}$, D. Palmer ${ }^{4}$. ${ }^{1}$ Rheumatology, Darent Valley Hospital, Dartford, United Kingdom; ${ }^{2}$ Community and Public health; ${ }^{3}$ Rheumatology and Rehabilitation, Ain Shams University, Cairo, Egypt; ${ }^{4}$ Rheumatology, North Middlesex University Hospital, London, United Kingdom

Objectives: 1. To compare the patient perspective on remission in RA in comparison to the rheumatologist perceived remission perspectives.

2. To determine the value of Patient Reported outcomes in identifying specific symptoms and aspects of disease able to define remission in RA from the patient perspective.

Methods: RA patients diagnosed according to ACR/EULAR criteria were treated according to treat-to-target regime with regular disease activity monitoring (every 1-3months). Remission was measured in two ways: 1) patient perceived remission using the question "Would you say that, at this moment, your disease activity is as good as gone? (yes/no)"; and 2) Physician perceived remission was defined as a physician global assessment $\leq 1$ on a $0-10$ VAS, phrased: "How active do you think the rheumatoid arthritis of your patient is today?" The study included 188 RA patients (76 males, 112 females; mean age $52.4 \pm 11$ years) and 87 rheumatologists ( 30 males, 57 females; mean age $48.7 \pm 11.7$ years). All participants were asked to complete a questionnaire which was composed of all domains identified in relation to the disease remission. $10 \mathrm{~cm}$ visual analogue scale (scored 0-10) was used to illustrate the importance of each factor in an individual opinion. The list included joint pain, functional ability, quality of life, absence of morning stiffness, absence of fatigue, normal laboratory tests, no comorbidity risk, radiologic remission, Disease Activity score and ability to work. In addition, patients were asked to complete a copy of the PROMs [1]. One-way analysis of variance was used for the comparison of independent variables. Spearman correlation coefficient was used to assess the correlation between variables.

Results: There were no significant differences in questionnaire answers in relation to patients' demographics and present disease activity. Regarding the patient perceived remission, the top 4 were: pain $(76 \%)$, functional ability $(71 \%)$, quality of life $(69 \%)$ and fatigue $(43 \%)$. Regarding the physician perceived remission, the following factors were rated more relevant by rheumatologists than the patients $(p<0.001)$ : low disease activity score $(88 \%)$, radiologic remission and progression of erosions $(76 \%)$, lab measures (ESR/CRP) $(57 \%)$ followed by difficulties in performing paid work $(49 \%)$.

Functional ability was scored significantly higher in patients $>65$ as compared with patients $<65$ years of age ( 9.6 vs 8.1 on VAS, $p=0.03$ ). In contrast the patient's cohort $<65$ years of age, rated quality of life at a higher level (9.7) than those below 65 (8.4). Functional ability was scored higher in patients with longer-standing disease as compared to patients with shorter disease duration $(p<0.05)$. PROMs enabled the patient and the treating physician identify the aspects of relevance necessary for optimal clinical management.

Conclusions: Different factors are important for rheumatologists and RA patients regarding disease remission. Treatment satisfaction is determined not only by disease activity indices but also by other patient-oriented factors. PROMs could optimise targeted therapy as it can play a significant role in identifying disease activity parameters relevant to both the treating rheumatologist as well as the patient.

References:

[1] El Miedany et al. Clin Exp Rheumatol 2010; 28(5):734-44.

Disclosure of Interest: None declared

DOI: 10.1136/annrheumdis-2017-eular.4491

\section{SAT0139 ASSESSING ENTHESITIS BY ULTRASONOGRAPHY IN PATIENTS WITH SERONEGATIVE RHEUMATOID ARTHRITIS}

Z. Erturk ${ }^{1}$, T. Özsoy ${ }^{2}$, I. Yağcı ${ }^{2}$, Y. Yalçınkaya ${ }^{1}$, Ü. Gazel ${ }^{1}$, P. Atagündüz ${ }^{1}$, H. Direskeneli ${ }^{1}$, N. İnanç ${ }^{1} .{ }^{1}$ Rheumatology; ${ }^{2}$ Physical Therapy and Rehabilitation, Marmara University, Istanbul, Turkey

Background: In patients with seronegative rheumatoid arthritis (RA) there is a difficulty to make the differential diagnosis with the spondyloarthropathies.

Objectives: To assess the presence of enthesitis in patients with seronegative rheumatoid arthritis in comparison with the healthy controls, patients with seropositive rheumatoid arthritis and ankylosing spondylitis.

Methods: In this cross-sectional study, seronegative and seropositive rheumatoid arthritis patients, who fulfilled the 2010 ACR/EULAR criteria, patients with ankylosing spondylitis and healthy controls have been assessed by grey scale and power doppler ultrasonography for the presence of enthesopathy at the achilles, plantar fascia, proximal patella, distal patella, quadriceps, tibialis anterior, triceps, common flexor and extensor tendons. Clinical assessment of the patient groups included demographic findings, health assessment questionnaire and disease activity score.

Results: In our study, we recruited age and sex matched 27 seronegative RA, 17 healthy controls, 20 seropositive RA and 12 ankylosing spondylitis patients. We evaluated and analysed both right and left sides of the enthesis regions separately which have been indicated in the methods section. The mean DAS28, mean ESR and mean CRP of the patients with seronegative RA were $3.6 \pm 1.28$, $32.2 \pm 21.2$ and $12.37 \pm 27.77$ respectively (Table 1 ).

Median of Madrid sonographic enthesitis index (MASEI) was 5 in patients with seronegative RA. 4 patients have severe scores. There were significant differences between seronegative RA and healthy controls $(3, p=0.014)$ but no differences has been observed between seronegative RA with seropositive RA (6) and anklosing spondylitis (7) in MASEI scores.

In comparison, hypoechogenicity of quadriceps tendon (16 $(29.6 \%)$ vs $1(2.5 \%)$, $p=0.001)$, bone erosion at the quadriceps tendon attachment (9 $(16.6 \%)$ vs 0 , $\mathrm{p}=0.007$ ), hypoechogenicity of triseps $(13(24 \%)$ vs $7(17.5 \%), p=0.049)$ have been observed more frequently in patients with seronegative RA than seropositive RA. Significantly higher number of patients with bone erosion at the distal patella $(10(41.6 \%)$ v $3(5.5 \%), p=<0.001)$, enthesophyte of achilles tendon $(7(29.1 \%)$ vs $2(3.7 \%), p=0.001)$ have been detected enthesophyte of proximal patella (7 $(29.1 \%)$ vs $0, p \leq 0.001)$ in patients with ankylosing spondylitis than seronegative RA.

Table 1

\begin{tabular}{lcccc}
\hline & $\begin{array}{c}\text { Seronegative } \\
\text { RA }\end{array}$ & $\begin{array}{c}\text { Healthy } \\
\text { controls }\end{array}$ & $\begin{array}{c}\text { Seropositive } \\
\text { RA }\end{array}$ & $\begin{array}{c}\text { Ankylosing } \\
\text { spondylitis }\end{array}$ \\
\hline Age, years & $51,85 \pm 11,49$ & $44,42 \pm 7,6$ & $52,05 \pm 11,26$ & $41,75 \pm 5,1$ \\
Women, $n$ (\%) & $48(88,9)$ & $34(100)$ & $36(90)$ & $20(83)$ \\
RA duration, year & $9,8 \pm 6,75$ & & $11,25 \pm 9,1$ & \\
RF titre (median) & $10,77 \pm 3,21$ & & $345,88 \pm 405,32$ & $12,1 \pm 3,23$ \\
Anti-CCP titre, median & $3,99 \pm 4,13$ & & $326,81 \pm 286,2$ & $4,32 \pm 3,7$ \\
DAS28, median & $3,6 \pm 1,28$ & & $3,73 \pm 1,45$ & \\
ESR, median & $32,2 \pm 21,2$ & $23,3 \pm 11,8$ & $41,63 \pm 28,07$ & $19,83 \pm 9,38$ \\
CRP, median & $12,37 \pm 27,77$ & $3,14 \pm 3,87$ & $14,34 \pm 19,97$ & $6,61 \pm 5,6$ \\
\hline
\end{tabular}

Conclusions: We observed that enthesis involvement was not seldom in patients with seronegative RA. Furthermore there were also similar frequency of entesis involvement in seropositive patients with RA. The value of enthesis sites evaluationfor the differential diagnosis of patients with seronegative RA should be further investigated and the assessment of enthesis sites in seronegative and seropositive RA patients can be important to detect active and chronic changes at the enthesis region.

Disclosure of Interest: None declared

DOI: 10.1136/annrheumdis-2017-eular.4457

\section{SATURDAY, 17 JUNE 2017 \\ Rheumatoid arthritis - anti-TNF therapy}

\section{SAT0140 EFFECT OF OBESITY IN RESPONSE TO BIOLOGICS IN RHEUMATOID ARTHRITIS}

A. Khan ${ }^{1}$, S. Sukumaran ${ }^{2}$, M. Kanitkar ${ }^{1}$, A.-S. Zafar ${ }^{2}$, S. Shah ${ }^{2}$, S. Adnan ${ }^{2}$. ${ }^{1}$ Department of Rheumatology, Queen Elizabeth Queen Mother Hospital, Margate; ${ }^{2}$ Department of Rheumatology, William Harvey Hospital, Ashford, United Kingdom

Background: Obesity epidemic has impacted practically every area of health including care of patients with RA. Adipose tissue is an active organ that produces pro-inflammatory molecules. A significant treatment challenge remains is the standard dose of RA medications may not attain same concentrations at sites of inflammation in obese vs non-obese patients thus making them less effective.

Objectives: The study aim was to determine whether obesity represents a risk factor for a poor remission in RA requiring biologic therapies. Obesity may be associated with more severe and refractory inflammation through increased levels of inflammatory adipocytokines leptin, resistin or visfatin or decreased levels of the anti-inflammatory adipocytokine adiponectin. We retrospectively analysed 178 patients diagnosed with RA at East Kent University Hospitals.

Methods: Data analysed for age, sex, disease duration, prior DMARD, positivity $\mathrm{RF}$ and anti-CCP antibodies and response to biologics DAS28 score pre-treatment and at 6 months were analysed.Main aim was to analyse any difference between obese and non-obese patients in terms of their response to treatment. Obese patients were defined with a BMI of 30 or above.

Results: See Table 1. 